\title{
Editorials
}

\section{Anxiety and depression in young adults and adolescents}

\section{INTRODUCTION}

Few professionals working in healthcare can fail to notice that there is a significant problem with the psychological wellbeing of many adolescents and young adults. As a GP and a consultant in emergency medicine, we annually attend numerous young patients presenting with any combination of anxiety, depression, and self-harm, yet this has not galvanised professional or public discourse in the way diabetes or obesity have. Of particular concern is the alarming apparent rise of these problems in girls and young women. A 2017 UK practice-based study of self-harm showed a $68 \%$ rise in incidence in girls aged 13-16 years between 2011-2014. There is, of course, no single explanation for this; however, the confluence of a number of factors suggests that millennials are less happy than earlier generations. These include increasing youth unemployment ${ }^{2}$ as well as loss of social mobility and decreasing affordability of housing delaying maturation into the independent adult role. ${ }^{3}$ More recently, there has been increasing interest in the role of social media in this matter.

\section{THE ROLE OF SOCIAL MEDIA}

Today's adolescents and young adults are more tech-savy than any previous generation; however, discussion of IT must acknowledge concerns about the potential negative consequences on psychological health, including its addictive potential. ${ }^{4}$ O'Keefe and Clarke-Pearson describe the phenomenon of 'Facebook depression' as a:

depression that develops when preteens and teens spend a great deal of time on social media sites, such as Facebook, and then begin to exhibit classic symptoms of depression [...] The intensity of the online world is thought to be a factor that may trigger depression. ${ }^{5}$

Mir and Novas note that self-confident youngsters able to project a selectively, often deceptively positive image may enjoy

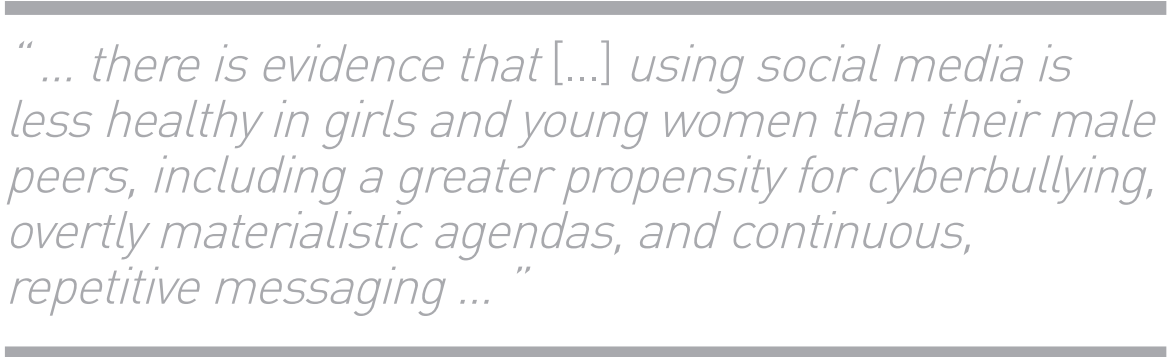

positive feedback in terms of numerous 'likes' while contributing to an increased and often exaggerated sense of inadequacy among peers with less flair. ${ }^{6}$ This has disproportionately affected females, ${ }^{7}$ and there is evidence that the mode of using social media is less healthy in girls and young women than their male peers, including a greater propensity for cyberbullying, ${ }^{8}$ overtly materialistic agendas, ${ }^{8}$ and continuous, repetitive messaging without pause for reflection. ${ }^{8}$ A recent study has also suggested that excessive social media use harms physical and psychological health by reducing exercise and sleep. ${ }^{?}$

The internet and social media have revolutionised the world; however, part of their maturation must include openness to debate the downside with a view to limiting damage, a process in which the participation of tech giants themselves is vital. While this article sounds a cautionary note about that downside, we believe that, when properly used and regulated, it can be a useful tool for acquiring knowledge, forming and maintaining friendships and relationships, and seeking help, including for health matters, possibly more so for vulnerable groups. Hammond et al have recently published qualitative research revealing that young people in care found use of social media of benefit in maintaining appropriate birth family relationships and friendships, making new connections, and transitioning into adult life. ${ }^{10}$ The Bridging the Digital Divide Report ${ }^{11}$ from Melbourne highlighted the benefits of online behaviour specifically for marginalised youth, including those in remote communities, same-sex attracted people, and indigenous Australians.

\section{CLINICAL MANAGEMENT}

The basic yet vital tool of history taking should routinely encompass asking about social media engagement in adolescents and young adults presenting with anxiety or depression, indeed, the HEADS4 social media screening questionnaire ${ }^{12}$ lan adaptation of the HEADSS questionnaire adding 'social media' as the fourth ' $S$ ') is well validated, and akin to the cut-annoyed-guiltyeye (CAGE) questionnaire for alcohol misuse. Beyond this, the recently updated National Institute for Health and Care Excellence (NICE) guidelines comprehensively cover all aspects of investigation and management. ${ }^{13}$ Following the blueprint for most psychological disorders, the advice is watchful waiting and pastoral support in mild cases, and if escalation is necessary, the choice lies between psychological therapies, pharmacotherapy, or both. ${ }^{13}$ Within talking therapies, cognitive behavioural therapy is the most popular and well known modality, and is a goal-focused, time-limited treatment underpinned by the reciprocal relationship between thoughts, feelings, and behaviour. ${ }^{13}$ With regard to pharmacotherapy, NICE recommends that in minors this should be initiated by child and adolescent psychiatrists. ${ }^{13}$ Selective serotonin reuptake inhibitors dominate, with the strongest evidence of efficacy for fluoxetine, which has a product licence from 8 years of age. ${ }^{13}$ Sertraline and citalopram are second-line treatments with licences only from 18 years of age, while there is little evidence to support any other drugs before adulthood. The recently published Pediatric Anesthesia Neurodevelopment Assessment (PANDA) study assessing the effectiveness of sertraline in primary care showed this 


\section{"If academic kudos is needed for a specialty's esteem, we aver that the shifting epidemiology of depression, especially the significant role of social media, forms fertile ground for vital clinical research.}

to improve anxiety, quality-of-life, and selfrated mental health, with weaker evidence for depression. ${ }^{14}$

\section{MAKING MENTAL HEALTH SERVICES MORE RESPONSIVE}

Despite the presence of guidelines, the reality for primary care and emergency medicine practitioners requesting help from mental health services is a distressingly familiar tale of long delays, rejected referrals, poor continuity of care, and early discharge more likely to reflect waiting list pressure than clinical need. Perhaps more than any other specialty within the NHS, mental health trusts are stricken by poor morale, high sickness absenteeism and staff turnover, and over-reliance on locums and bank nurses leading to poorer outcomes for patients, ${ }^{15}$ which may well perpetuate the vicious cycle by making those vacant posts less attractive to prospective applicants. The NHS Mental Health Implementation Plan recognises this, ${ }^{16}$ and has bold aims to boost staffing levels over the next half-decade, but this appears overly optimistic given the current economic climate. Yet the sheer volume of human distress and resulting clinical demand means that mental health needs that support. If academic kudos is needed for a specialty's esteem, we aver that the shifting epidemiology of depression, especially the significant role of social media, forms fertile ground for vital clinical research. This, in turn, presents an opportunity to cast the recruitment and retention net more imaginatively if, for example, NHS trusts and universities co-operate to create research fellowships enabling postgraduate

\section{ADDRESS FOR CORRESPONDENCE}

\section{Edin Lakasing}

Chorleywood Health Centre, 15 Lower Road,

Chorleywood, Hertfordshire WD3 5EA, UK.

\section{Email: edin.lakasinganhs.net}

doctors, nurses, and psychologists to pursue academia alongside a clinical commitment. Many of those posts could reasonably bridge the primary-secondary interface and be at least in part based in general practice and emergency departments.

\section{CONCLUSION}

It is beyond doubt that anxiety and depression in adolescents and young adults represents a significant workload and public health matter. A rapidly changing epidemiology means that both health services and wider society must adapt to become more responsive to current need, in tandem with participating in future risk reduction strategies.

\section{Edin Lakasing,}

GP and Trainer, Chorleywood Health Centre, Chorleywood, Hertfordshire.

\section{Zul Mirza}

Consultant in Emergency Medicine, West Middlesex University Hospital, Isleworth, Middlesex.

\section{Provenance}

Freely submitted; externally peer reviewed.

\section{Competing interests}

The authors have declared no competing interests.

DOI: https://doi.org/10.3399/bjgp20X707765

\section{REFERENCES}

1. Morgan C, Webb RT, Carr MJ, et al. Incidence, clinical management, and mortality risk following self-harm among children and adolescents: cohort study in primary care. BMJ 2017; 359: j4351.

2. Lakasing $E$. Youth unemployment: a public health problem set to worsen if older people work longer. Br J Gen Pract 2013; DOI: https:// doi.org/10.3399/13X669248.

3. Howker E, Malik S. Jilted generation: how Britain has bankrupted its youth. London: Icon Books, 2010.

4. Zendle $\mathrm{D}$, Bowden-Jones H. Is excessive use of social media an addiction? BMJ 2019; 365: 12171.

5. O'Keeffe GS, Clarke-Pearson K, Council on Communications and Media. The impact of social media on children, adolescents, and families. Pediatrics 2011; 127(4): 800-804

6. Mir E, Novas C. Social media and adolescents and young adults' mental health. 2019. http:// unw.center4research.org/social-media-affectsmental-health/ (accessed 16 Dec 2019).

7. Collishaw S. Annual research review: secular trends in child and adolescent mental health. J Child Psychol Psychiatry 2015; 56(3): 370-393.

8. Augner C, Hacker GW. Associations between problematic mobile phone use and psychological parameters in young adults. Int $\mathrm{J}$ Public Health 2012; 57(2): 437-441.

9. Viner RM, Aswathikutty G, Stiglic N, et al. Roles of cyberbullying, sleep, and physical activity in mediating the effects of social media use on mental health and wellbeing among young people in England: a secondary analysis of longitudinal data. Lancet Child Adolesc Health 2019; 3(10): 685-696.

10. Hammond SP, Cooper N, Jordan P. Social media, social capital and adolescents living in state care: a multi-perspective and multimethod qualitative study. The British Journal of Social Work 2018; 48(7): 2058-2076.

11. Blanchard M, Metcalf A, Burns J. Bridging the digital divide: creating opportunities for marginalised young people to get connected. 2007. https://uww.vichealth.vic.gov.au/mediaand-resources/publications/bridging-the-digitaldivide (accessed 16 Dec 2019).

12. Clark DL, Raphael JL, McGuire AL. HEADS 4: social media screening in adolescent primary care. Pediatrics 2018; 141(6): e20173655.

13. National Institute for Health and Clinical Excellence. Depression in children and young people: identification and management. NG134. 2019. https://unw.nice.org.uk/guidance/NG134 laccessed 16 Dec 2019).

14. Lewis G, Duffy L, Ades A, et al. The clinical effectiveness of sertraline in primary care and the role of depression severity and duration (PANDA): a pragmatic, double-blind, placebocontrolled randomised trial. Lancet Psychiatry 2019; 6(11): 903-914.

15. Jackson C. Slaves to the machine. Therapy Today 2019; 30(4).

16. NHS Digital. NHS mental health implementation plan 2019/20-2023/24. 2019. https:// uww.longtermplan.nhs.uk/wp-content/ uploads/2019/07/nhs-mental-healthimplementation-plan-2019-20-2023-24.pdf (accessed 16 Dec 2019). 